\title{
Enhancement of dyeing cotton fabrics using nanocomposite
}

\author{
Mehrez E.El-Naggar ${ }^{1}$, H.M.Mashaly ${ }^{2}$ and Mohamed Rehan ${ }^{1}$ \\ ${ }^{1}$ Pre-Treatment and Finishing of Cellulosic Fabric Department, Textile Industries \\ Research Division, ${ }^{2}$ Dyeing, Printing and Auxiliaries Department, Textile Industries \\ Research Division, National Research Centre, Dokki, Giza, Egypt
}

\begin{abstract}
A CTUALLY, the present current work addresses an innovative approach for benign enhancement of dyeing of cotton fabrics assisted with nanocomposite based on chitosan (Cs), silver nanoparticles (Ag NPs) and clay. The Cs/Ag NPs and Cs/Ag NPs/clay nanocomposites were prepared using UV irradiation and applied on the cotton fabrics by paddry-curing method. The blank and treated cotton fabrics were dyed with C.I. Acid Orange 74. The Dye exhaustion, colorimetric analysis as well as fastness properties of the treated fabrics was evaluated. The obtained data proves that the nanocomposite of Cs/Ag NPs/clay is a promising mixture for durable dyeing for cotton fabrics.
\end{abstract}

Keywords: Cotton Fabrics; Dyeing; Nanocomposite; Acid Dye; Chitosan; Silver NPs; Clay.

\section{Introduction}

High performance cellulosic based fabrics with dual or multi-functional surfaces, is usually used to increase the textiles versatility [1-13]. Coloration of technical textiles is performed either by dyeing to form uniform color or by printing to introduce a design or a pattern to a fabric. Dye molecule structure contain of two key parts: the chromophores, responsible for creating the color, and the auxochromes, which can not only increment the chromophore but also render the molecule soluble in water and give improved affinity toward the fibers [14]. Acid dye is a material used in textile dyeing. The naming of the acid dye develops from the use of an acid in the solution. Acid dye is usually a sodium salt of sulfonic acid, or at least, it is an ionic carboxylic acid which turns into an anion in a solution. It will dye the fibers in the cationic part [15]. It is usually substituted with ammonium ion groups in fibers such as wool, silk and nylon [16-19]. This fiber will absorb the acid. The acid wills protonate the amino group of fibers, so they become cationic. Dyeing process involves exchange of the anion associated with an ammonium ion in the fiber with a dye anion in the bath [20-22]. The cotton fabrics are hydrophilic fabrics whose structures are cellulose polymers with varying degree of polymerization (DP). The primary -OH group of cellulose is a functional group that acts to bond with the dyestuff $[23,24]$. The use of acid dye causes less affinity to cotton fabric because of no cationic part in cotton surfaces. The Chemical modification of cotton fabrics for improving utilization of acid dyes has attracted much attention. The process is primarily to attach the cationic compounds on cotton fabrics by chemical binding or physical adsorption for enhancing the substantively between anionic dye and cotton [25-27]. Such treated cotton would be dyeable with acid dyes under neutral or mildly acidic conditions in the absence of electrolyte in the dyebath $[28,29]$. In this research, the utilization of nanocomposite in the textile fields is examined by preparation and deposition of the Cs, Cs/Ag NPs and Cs/Ag NPs/ clay nanocompoites. The nanocompoites deposited on the cotton surface will be dyed by the acid dyes.

\section{Materials and methods}

\section{Materials}

Scoured and bleached 100\% cotton fabric (140 g) $\mathrm{m}^{2}$ ) was supplied by El-Mahalla El-Kobra Company. The fabrics were scoured in aqueous solution with a liquor ratio1:50 containing $5 \mathrm{~g} / 1$ nonionic detergent solution (Hostapal, Clariant) and $2 \mathrm{~g} / 1 \mathrm{Na}_{2} \mathrm{CO}_{3}$ at $95^{\circ} \mathrm{C}$ for $4 \mathrm{hr}$. to remove impurities, then rinsed thoroughly in cold tap water, and dried at room temperature. C.I. Acid Orange 74 as model acid dye. 


\section{Methods}

Preparation of Cs/Ag NPS/clay nanocomposite

Clay solution ( $1 \%$ ) was prepared by dissolving $1 \mathrm{~g}$ in $100 \mathrm{~mL}$ deionized water under magnetic stirring for $1 \mathrm{~h}$ then sonicated for another $1 \mathrm{~h}$. The $\mathrm{CS} / \mathrm{Ag}^{+}$composite was prepared by dissolving 2 $\mathrm{g}$ of $\mathrm{Cs}$ in $100 \mathrm{ml}$ of $1.0 \mathrm{Wt} \%$ acetic acid under constant magnetic stirring for overnight. After complete dissolution, $100 \mathrm{mg} / \mathrm{l}$ of silver nitrate $\left(\mathrm{AgNO}_{3}\right)$ was added slowly to Cs solution under contentious stirring. Then, the clay suspension was added to the $\mathrm{CS} / \mathrm{Ag}^{+}$composite vigorously stirred for $4 \mathrm{~h}$ at room temperature. The $\mathrm{CS} / \mathrm{Ag}^{+} /$ clay was irradiated using the UV range (320-400 $\mathrm{nm}$ ) with a UV lamp at $1=350 \mathrm{~nm}$, photon energy 2.26-3.94 eV emitting $668 \mu \mathrm{W} \mathrm{cm} \mathrm{cm}^{-2}$ at a distance of $5 \mathrm{~cm}$ for $2 \mathrm{~h}$. The color of prepared sample was gradually changed from colorless to light gray, then to gray and finally to dark gray [30].

Finishing cotton fabric with the as prepared nanocomposites

Bleached cotton fabrics were washed with $1 \mathrm{~g} / \mathrm{L}$ nonionic detergent at $90{ }^{\circ} \mathrm{C}$ for $15 \mathrm{~min}$ to remove impurities. The pretreated cotton fabrics were immersed for $1 \mathrm{~h}$ in $\mathrm{Cs}(2 \%)$, and the same concentrations of the as prepared Cs/Ag NPs and $\mathrm{Cs} / \mathrm{Ag}$ NPs/clay nanocomposites that are mentioned before. The treated samples were squeezed to $100 \%$ wet pick-up using pad-dry-cure method at constant pressure. Samples were dried at $90{ }^{\circ} \mathrm{C}$ for $5 \mathrm{~min}$, followed by curing at $140{ }^{\circ} \mathrm{C}$ for $1 \mathrm{~min}$ to fix the as prepared nanocomposite into and on the surface of cotton fabrics.

Dyeing process of untreated and treated cotton fabric with Cs/Ag NPs/clay

Dyeing process of blank and treated cotton fabric was carried out at $100{ }^{\circ} \mathrm{C}$, L.R 1:40 .Dyeing baths contains $2 \%$ (w.o.f) dye at $\mathrm{pH} 5$. The fabric was immersed and the temperature was raised to $100{ }^{\circ} \mathrm{C}$ and the dyeing continued for $60 \mathrm{~min}$. At the end of dyeing, the dyed samples were rinsed with tap water and allowed to dry in open air. The dyed samples were rinsed with water and washed in a bath L.R. using $3 \mathrm{~g} \backslash \mathrm{l}$ of nonionic detergent Hostabal Clarinet at $600 \mathrm{C}$ for $30 \mathrm{~min}$. Subsequently, they were rinsed and dried at ambient temperature [31].

\section{Characterization}

\section{Dye exhaustion}

The extent of dye exhaustion (\%) achieved for an appropriate dye concentration on each of the two types of dyes was determined by the absorbance spectroscopic analysis of the dyebath before and after dyeing on Shimadzu UV-2401PC
$\mathrm{UV} / \mathrm{vis}$ spectrophotometer at maximum wave length for each dye. The percentage of dye-bath exhaustion (\% E) was calculated using Eq. (1):

$$
\% \mathrm{E}=\mathrm{A}_{1}-\mathrm{A}_{2} / \mathrm{A}_{1} \times 100
$$

where $A_{1}, A_{2}$ are the concentrations of the dyebath before and after dyeing, respectively.

\section{Colorimetric analysis}

The colorimetric analysis of the colored fabrics was recorded using a spectrophotometer with pulsed xenon lamps as a light source (UltraScan (Pro, Hunter Lab, USA) $10^{\circ}$ observer with D65 illuminant, $\mathrm{d} / 2$ viewing geometry and measurement area of $2 \mathrm{~mm}$. All measurements were acquired at $\lambda_{425} \mathrm{~nm}$ wavelength. The corresponding color strength value $(\mathrm{K} / \mathrm{S})$ was assessed by applying the Kubelka-Munk equation (Eq. 2) $[1,2]$ sunlight can also be a source of such deleterious effects as sunburn, and suntanning, as well as premalignant and malignant lesions. These may all occur in individuals with normal responses to sunlight. In addition, there exist a variety of 'abnormal' photosensitivity responses to sunlight that may result from either endogenous imbalances (e.g. the porphyrias:

$$
K / S=\frac{(1-R)^{2}}{2 R}
$$

where $\mathrm{R}$ is the decimal fraction of the reflection of the colored fabric, $\mathrm{K}$ is the absorption coefficient and $\mathrm{S}$ is the scattering coefficient. The total color difference $(\Delta \mathrm{E})$ was represented in terms of CIE LAB color space data. The CIE LAB color space data $\left(L^{*}, a^{*}, b^{*}\right)$ of colored samples was measured by the same spectrophotometer used for measuring color strength at the same setup, and then the color difference was calculated using (Eq. 3),

$$
\Delta \mathrm{E}=\mathrm{L}^{2}+\left[\left(\mathrm{a}^{2}+\mathrm{b}^{2}\right)\right]^{1 / 2}
$$

where, $\Delta \mathrm{E}$ is the total difference between the sample and the stander, $\mathrm{L}$ is the lightness from black (0) to white $(100), a^{*}$ is the red $(+) /$ green $(-)$ ratio and $b^{*}$ is the yellow $(+) /$ blue $(-)$ ratio. The color fastness of the treated fabrics was tested according to ISO standard methods. The specific tests were ISO 105-X12 (1987) for color fastness to rubbing; ISO 105-C02 (1989) for color fastness to washing and ISO 105 E04 (1989) for color fastness to perspiration [9].

\section{Results and discussion}

Preparation and characterization of $\mathrm{CS} / \mathrm{Ag} \mathrm{NPs} /$ clay composite and treated cotton fabrics

The formation of Ag NPs was visually observable by the color change in the treatment 
solution from colorless to a color. The UV-vis spectroscopy is a simple and sensitive technique for the characterization of Ag NPs. The typical UV-vis absorption spectra of the resulting solution of Ag NPs synthesized under UV radiation are shown in Figure 1.

It is clearly observable in figure $\mathbf{1}$ that, there is no absorption in visible region for the composite of $\mathrm{Cs} / \mathrm{Ag}^{+} /$clay. However, the absorption band around $400 \mathrm{~nm}$ is appearing in the absorption spectra composite sample of $\mathrm{Cs} / \mathrm{Ag} \mathrm{NPs} /$ clay prepared using $2 \mathrm{~h}$ irradiation time. Hybrid nanocomposites of Cs/Ag NPs/clay were applied to cotton fabric using pad- dry -cure method. The treated cotton fabrics with the as prepared nanocomosites of $\mathrm{Cs} / \mathrm{Ag}$ NPs/clay when compared with the blank cotton fabric only are visibly evident as the color is changed from colorless to yellow darkness. The morphological of the untreated and treated cotton fabric surface with $\mathrm{Cs}$, Cs/Ag NPs and $\mathrm{Cs} / \mathrm{Ag} \mathrm{NPs} /$ clay is observed by using FE-SEM and the resulted images are showed in Figure 2.
It is clearly seen that the untreated sample has a relatively smooth surface as shown in Figure 2 (A, a) at low and high magnification indicating that there are no nanoparticles on the surface. After treating with Cs solution, film of Cs is covered on the fabric surface, beside the formed Cs film, the surface becomes rough due to the effect of Cs polymer as displayed in Figure $2(\mathrm{~B}, \mathrm{~b})$. Figure 2C shows the SEM micrographs of the treated cotton fabrics with $\mathrm{Cs} / \mathrm{Ag} \mathrm{NPs}$. It is observed that the Ag NPs are deposited on the surface of cotton fabrics. In addition, the obtained SEM graph at high magnification (8000X) indicating that the particles of Ag NPs are distributed on the fabrics uniformly. It is noticed that the Cs/Ag NPs nanocomposites is spherical with small diameter. It can be seen that the treated cotton fabric sample with colloidal dispersion of hybrid composite $\mathrm{Cs} / \mathrm{Ag}$ NPs/Clay appears to be covered with aggregated nanocomposite and the rough surface is obtained. The low and high magnification (Figure $2 \mathrm{D}$ and $\mathrm{d}$ ) show a formation of aggregated clay minerals on the surface of cotton.

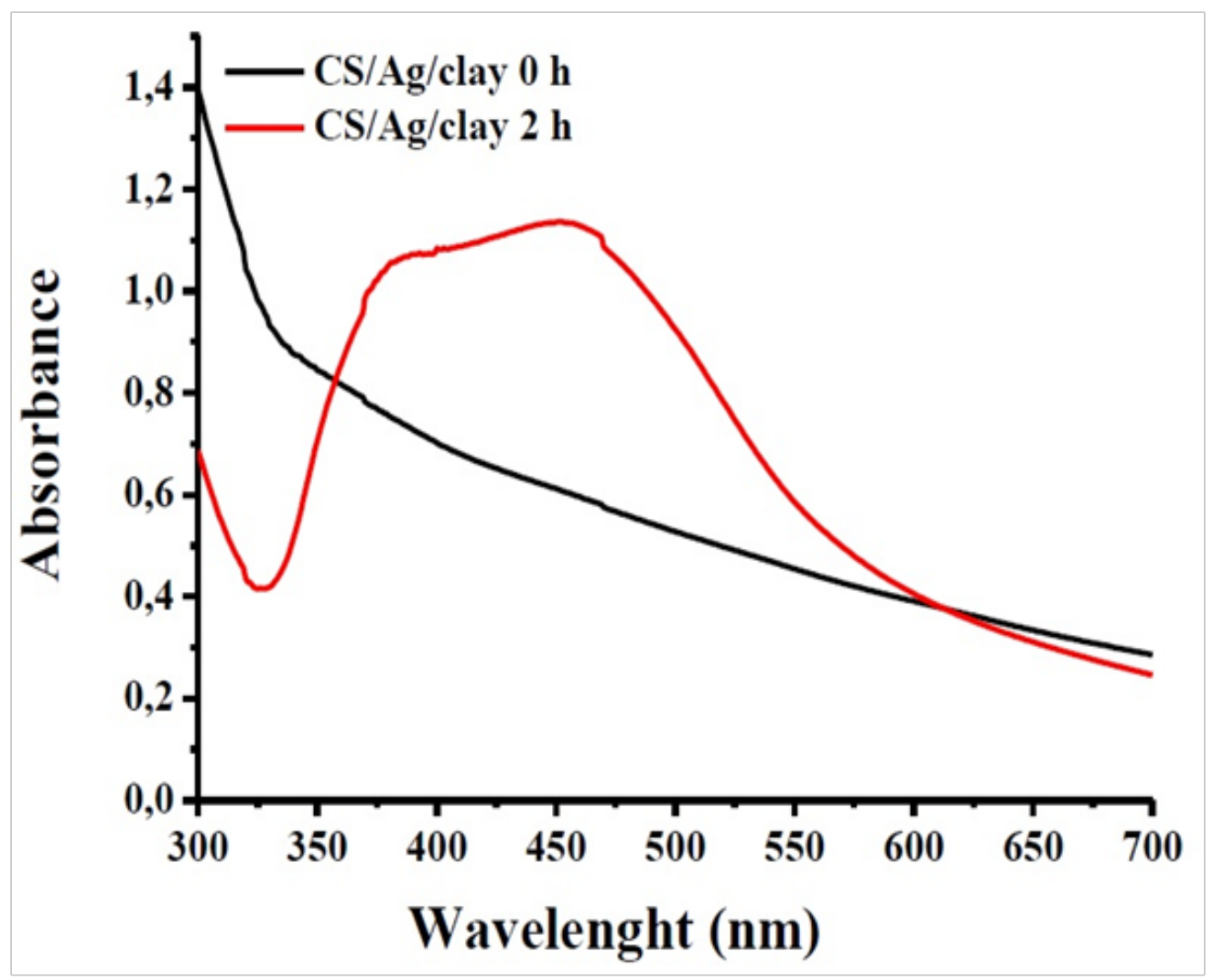

Fig. 1. Surface Plasmon resonance peak of $\mathrm{Cs} / \mathrm{Ag}$ NPs/clay nanocomposite. 


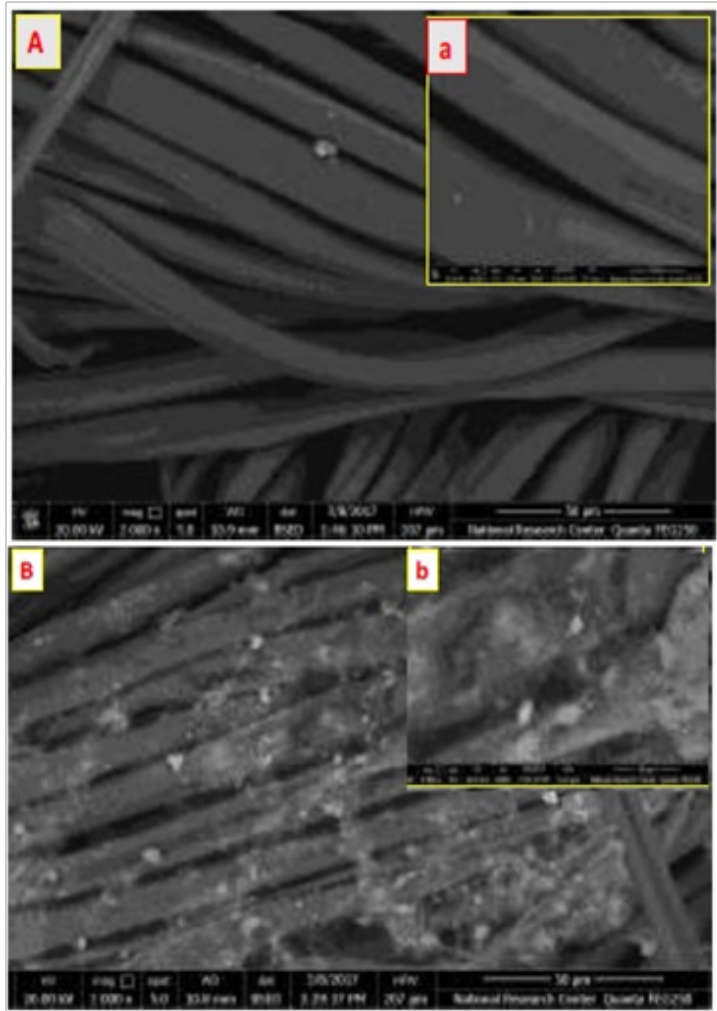

Fig. 2. Low and high magnification SEM images of $(A, a)$ untreated cotton fabrics, $(B, b)$ cotton fabrics treated with Cs/AgNPs/clay.

The nanocomposites of the Cs/Ag NPs with and without clay were coated on the cotton fabric using pad- dry -cure method. The influence of these hybrid nanocomposites on the fabric the mechanical properties and compared with untreated cotton fabrics are examined and the value of Tensile strength $(\mathrm{N} / \mathrm{cm} 2)$ and elongation (\%) are recorded in Table 1.

It is seen that the tensile strength of untreated cotton fabric is $555 \mathrm{~N} / \mathrm{cm}^{2}$ and increase to $567 \mathrm{~N} / \mathrm{cm}^{2}$ for the treated fabric with $\mathrm{Cs}$ and $\mathrm{Cs} / \mathrm{Ag}$ NPs. The value of tensile strength is sharply increase $(667 \mathrm{~N} /$ $\mathrm{cm}^{2}$ ) with the addition of clay to the nanocomposite of Cs/Ag NPs. Opposite trend is observed with the elongation at break. The latter decreases by the addition of clay to $\mathrm{Cs} / \mathrm{Ag} \mathrm{NPs}$ nanocomposite. It is concluded that the high improvement in tensile strength may be achieved by adding clay to the hybrid nanocomposite of Cs/Ag NPs.

Dyeing of raw and treated cotton fabrics with acid dye

The coloration process of textile fabrics is an important aesthetic property for textiles end use and this process has evolved to be a crucial process. The Acid dyes are the salts of carboxylic acids or sulfonate can be dissolute in aqueous

J. Text. Color. Polym. Sci. 16, No. 1 (2019) solutions leaving the anionic character to the chromophore unit, so these dyes show higher affinity towards cationic charged fibers like wool, silk and nylon. According to this behavior, the acid dyes are not used for cellulosic fibers/fabrics coloration. However, the fact that, the modification of cellulosic fibers/fabrics can be effectively on coloration of cotton fabrics with acid dye. In this study, the cotton fabric as cellulosic fabric was modified with different agents to show the influence of these modified on the coloration of cotton with acid dye.

To clarify the influence of different modified agent on the color of treated cotton fabrics, the dye exhaustion (\%) as well as the color strength $(\mathrm{K} / \mathrm{S})$ was evaluated (Table 2 . The color strength $(\mathrm{K} / \mathrm{S})$ value is commonly used to refer the amount of the dye content of the colored fabrics where, higher $\mathrm{K} / \mathrm{S}$ value shows greater color intensity and hence better amount of dye incorporated into the fabrics.

It was observed from Table 2 that; the dye exhaustion (\%) and the color strength $(\mathrm{K} / \mathrm{S})$ of treated cotton fabrics are higher than untreated cotton fabric. This result indicates that, the modification of cotton fabrics with different agent can improved significantly the dyeability 
TABLE 1. Mechanical Properties of cotton fabrics.

\begin{tabular}{ccc}
\hline Sample & Tensile strength $\left(\mathbf{N} / \mathbf{c m}^{2}\right)$ & Elongation (\%) \\
\hline Blank cotton fabric & $590 \pm 20$ & $16.12 \pm 3$ \\
$\mathrm{CS} /$ cotton fabric & $563 \pm 17$ & $16.11 \pm 1$ \\
$\mathrm{CS} / \mathrm{Ag}$ NPs/ cotton fabric & $564 \pm 13$ & $15.93 \pm 1$ \\
$\mathrm{CS} / \mathrm{Ag} \mathrm{NPs} /$ clay/ cotton fabric & $656 \pm 11$ & $17.32 \pm 1$ \\
\hline
\end{tabular}

TABLE 2. The dve exhaustion (\%) and color strength (K/S) of the dved cotton fabric with C.J. Acid orange 74).

\begin{tabular}{|c|c|c|}
\hline Sample & Exhaustion \% & K/S \\
\cline { 3 - 3 } Untreated cotton fabric & 12 & 1.2 \\
\hline Chitosan/ cotton fabric & 62 & 13.58 \\
\hline Chitosan /Ag NPs/ cotton fabric & 45 & 10.12 \\
\hline Chitosan /Ag NPs/clay/ cotton fabric & 38 & 7.67 \\
\hline
\end{tabular}

of cotton fabrics with acid dye. The cotton fabric treated with chitosan show the highest dye exhaustion (\%) and the color strength $(\mathrm{K} / \mathrm{S})$. This is the enhancement may be attributed to that, the most of the amino groups of chitosan will be existed in protonated form $-\mathrm{NH}^{+3}$ in $\mathrm{pH}(4-5)$, so the chitosan treatment can be created of a positive cationic $-\mathrm{NH}^{+3}$ sites on cotton macromolecules resulting in higher accessibility to attract anionic negatively charged acid dye via ionic attractive forces. Thus, the number of positive charges on the cotton fabric surface will be a decisive factor in determining the extent of ionic attraction between acid dye and fabric and subsequently the obtained dye exhaustion (\%) and the color strength $(\mathrm{K} / \mathrm{S})$. The presence of Ag NPs or clay with chitosan may be decrease the positive cationic charge occupied surface and decrease the attractive forces between acid dye and cotton fabric surfaces decreasing the dye exhaustion $(\%)$ and the color strength $(\mathrm{K} / \mathrm{S})$ for cotton sample.[32-36]

The CIE (L*, a*, b*) system was used to investigate and evaluate the color coordinates where, $\mathrm{L}^{*}$ refers to lightness/darkness values from 100 to 0 representing white to black, $a^{*}$ is the values run from negative (green) to positive (red) and, $b^{*}$ values run from negative (blue) to positive (yellow). The colorimetric data of blank and treated fabrics were provided in Table 3.
Data of this table illustrated that, the original color of raw cotton fabrics is white with high $\mathrm{L}^{*}$ value (82.86), low a* value (1.91) and negative $b^{*}$ values (-7.82). On the other side, the dyed cotton samples have significantly change of $\left(\mathrm{L}^{*}, \mathrm{a}^{*}, \mathrm{~b}^{*}\right)$ values compared to the blank ones. Where, $\left(\mathrm{L}^{*}\right)$ is significantly decreased while $a^{*}$ and $b^{*}$ values are increased dramatically. The deeper color leads to higher total color difference values. A more decrease in $\mathrm{L}^{*}$ values could be due to more colorant penetrations into cotton samples indicating more dyeability. The results showed that both the color components $a^{*}$ and $b^{*}$ almost increased by cotton surface modifications indicating more dye-ability of all modified cotton fabrics. The $b^{*}$ values became more positive indicating more yellow part in color and the more positive $\mathrm{a}^{*}$ value indicating more red in color and the combination of $b^{*}$ and $a^{*}$ changes thus evaluating the increase in orange color of treated cotton fabrics. The more scientific change in $b^{*}$ and $a^{*}$ values was obtained in the cotton fabric treated with chitosan. It can be easily concluded that the cotton fabric treated with chitosan show the highest deep color intensity indicating more dye-ability. This behavior was also in agreement with dye exhaustion (\%) and the color strength $(\mathrm{K} / \mathrm{S})$ data discussed earlier. In addition, the different color fastness properties of colored fabrics were measured and the results are reported in Tables 4.

J. Text. Color. Polym. Sci. 16, No. 1 (2019) 
TABLE 3. Colorimetric data of the dyed cotton fabric with C.I. Acid orange 74).

\begin{tabular}{|c|c|c|c|}
\hline Sample & $\mathbf{L}^{*}$ & $\mathbf{a}^{*}$ & $\mathbf{b}^{*}$ \\
\hline Raw cotton fabrics & 82.86 & 1.91 & -7.82 \\
\hline Untreated cotton fabric & 76.66 & 7.38 & 12.94 \\
\hline CS/ cotton fabric & 49.44 & 42.87 & 46.39 \\
\hline CS/Ag NPs/ cotton fabric & 54.09 & 41.01 & 47.61 \\
\hline CS/Ag NPs/clay/ cotton fabric & 61.39 & 36.47 & 47.79 \\
\hline
\end{tabular}

TABLE 4. Fastness properties of the dyed cotton fabrics with the acid dye.

\begin{tabular}{|c|c|c|c|c|c|c|c|c|c|c|c|c|}
\hline \multirow{3}{*}{ Samples } & \multicolumn{2}{|c|}{ Rubbing } & \multicolumn{3}{|c|}{ Washing } & \multicolumn{6}{|c|}{ Perspiration } & \multirow[t]{3}{*}{ Light } \\
\hline & \multirow{2}{*}{ Dry } & \multirow{2}{*}{ Wet } & \multirow{2}{*}{ Alt. } & \multirow{2}{*}{ St.* } & \multirow{2}{*}{ St.** } & \multicolumn{2}{|c|}{ Acidic } & \multicolumn{4}{|c|}{ Alkaline } & \\
\hline & & & & & & Alt. & St.* & St. $* *$ & Alt. & St.* & St. $* *$ & \\
\hline Blank cotton fabric & 2 & $2-3$ & $2-3$ & 3 & $2-3$ & 2 & $2-3$ & $2-3$ & 3 & $2-3$ & 3 & 2 \\
\hline $\mathrm{CS} /$ cotton fabric & $3-4$ & 3 & 4 & 4 & 4 & 4 & 4 & 4 & 4 & 4 & 4 & 6 \\
\hline $\begin{array}{c}\mathrm{CS} / \mathrm{Ag} \mathrm{NPs} / \text { cotton } \\
\text { fabric }\end{array}$ & 4 & 3 & 4 & $4-5$ & 4 & 4 & 4 & 4 & 4 & 4 & 4 & $5-6$ \\
\hline $\begin{array}{l}\text { CS/Ag NPs/clay/ } \\
\text { cotton fabric }\end{array}$ & 4 & 4 & $4-5$ & $4-5$ & 4 & $3-4$ & 4 & $3-4$ & 4 & 4 & $3-4$ & 5 \\
\hline \multicolumn{13}{|c|}{ 1t.: alteration } \\
\hline
\end{tabular}

In this table it is clear that, modified cotton fabrics were exhibited very good results for rubbing, washing, perspiration, and for light properties rather than un-modified cotton fabrics. these good fastness properties for the applied acid dye can be discussed in terms of the chemical structure of the dye used and that of modified cotton fabrics which may cause the dye to be tightly adhered to the modified cotton fabrics to the degree that caused this observed improve in fastness properties.

\section{Conclusion}

Research adopted in this study is undertaken with a view to enhancement of dyeing of the cotton fabrics with acid dyes using nanocomposites. Blank cotton fabrics and modified with $\mathrm{Cs}, \mathrm{Cs} / \mathrm{Ag}$ $\mathrm{NPs}$ and $\mathrm{Cs} / \mathrm{Ag} \mathrm{NPs} / \mathrm{clay}$ was dyed with C.I. Acid Orange 74 that otherwise have little substantively towards cellulosic fabrics. The results showed that, the good exhaustion $\%, \mathrm{~K} / \mathrm{S}$, colorimetric data and good fasteners properties were obtained for modified cotton fabrics in this order CS/ cotton fabric $>\mathrm{CS} / \mathrm{Ag} \mathrm{NPs} /$ cotton fabric $>\mathrm{CS} / \mathrm{Ag} \mathrm{NPs} /$ clay/ cotton fabric.

\section{References}

1. El-Naggar ME, Shaarawy S, Hebeish A. Multifunctional properties of cotton fabrics coated with in situ synthesis of zinc oxide nanoparticles capped with date seed extract. Carbohydrate polymers. 181, 307-16, 2018

2. El-Naggar ME, Shaarawy S, Hebeish A. Bactericidal finishing of loomstate, scoured and bleached cotton fibres via sustainable in-situ synthesis of silver nanoparticles. International journal of biological macromolecules. 106, 1192-202, 2018.

3. Hassabo AG, El-Naggar ME, Mohamed AL, Hebeish AA. Development of multifunctional modified cotton fabric with tri-component nanoparticles of silver, copper and zinc oxide. Carbohy drate Polymers. 210, 144-56, 2019. 
4. [El-Naggar ME, Hassabo AG, Mohamed AL, Shaheen TI. Surface modification of $\mathrm{SiO} 2$ coated $\mathrm{ZnO}$ nanoparticles for multifunctional cotton fabrics. Journal of Colloid and Interface Science. 498, 413-22, 2017.

5. Mohamed AL, El-Naggar ME, Shaheen TI, Hassabo AG. Laminating of chemically modified silan based nanosols for advanced functionalization of cotton textiles. International Journal of Biological Macromolecules. 95, 429-37, 2017.

6. Yan J, Abdelgawad AM, El-Naggar ME, Rojas OJ. Antibacterial activity of silver nanoparticles synthesized In-situ by solution spraying onto cellulose. Carbohydrate Polymers. 147, 500-8, 2016.

7. Shaheen TI, El-Naggar ME, Abdelgawad AM, Hebeish A. Durable antibacterial and UV protections of in situ synthesized zinc oxide nanoparticles onto cotton fabrics. International Journal of Biological Macromolecules. 83, 426-32, 2016.

8. Rehan M, Barhoum A, Van Assche G, Dufresne A, Gätjen L, Wilken R. Towards multifunctional cellulosic fabric: UV photo-reduction and in-situ synthesis of silver nanoparticles into cellulose fabrics. International Journal of Biological Macromolecules. 98, 877-86, 2017.

9. Emam HE, Mowafi S, Mashaly HM, Rehan M. Production of antibacterial colored viscose fibers using in situ prepared spherical Ag nanoparticles. Carbohydrate Polymers. 110, 148-55, 2014.

10. Rehan M, Mowafi S, Abdelmoez Aly S, Elshemy NS, Haggag K. Microwave-heating for in-situ Ag NPs preparation into viscose fibers. European Polymer Journal.86, 68-84, 2017.

11. Rehan M, Mashaly HM, Mowafi S, Abou El-Kheir A, Emam HE. Multi-functional textile design using in-situ Ag NPs incorporation into natural fabric matrix. Dyes and Pigments. 118, 9-17, 2015.

12. Rehan M, Khattab TA, Barohum A, Gätjen L, Wilken R. Development of $\mathrm{Ag} / \mathrm{AgX}(\mathrm{X}=\mathrm{Cl}, \mathrm{I})$ nanoparticles toward antimicrobial, UV-protected and self-cleanable viscose fibers. Carbohydrate Polymers. 197, 227-36, 2018.

13. Rehan M, Barhoum A, Khattab TA, Gätjen L, Wilken R. Colored, photocatalytic, antimicrobial and UV-protected viscose fibers decorated with Ag/Ag 2 CO 3 and Ag/Ag 3 PO 4 nanoparticles. Cellulose.1-17.

14. El Bouraie M, El Din WS. Biodegradation of Reactive Black 5 by Aeromonas hydrophila strain isolated from dye-contaminated textile wastewater. Sustainable Environment Research. 26(5), 209-16, 2016.

15. Dos Santos AB, Cervantes FJ, Van Lier JB. Review paper on current technologies for decolourisation of textile wastewaters: perspectives for anaerobic biotechnology. Bioresource technology. 98(12),2369-85, 2007.

16. Sun J, Wang H, Zheng C, Wang G. Synthesis of some surfactant-type acid dyes and their low-temperature dyeing properties on wool fiber. Journal of Cleaner Production. 2019.

17. Ferrero F, Periolatto M. Ultrasound for low temperature dyeing of wool with acid dye. Ultrasonics Sonochemistry. 9(3), 601-6, 2012.

18. Khan MMR, Tsukada M, Gotoh Y, Morikawa H, Freddi G, Shiozaki H. Physical properties and dyeability of silk fibers degummed with citric acid. Bioresource technology. 101(21), 8439-45, 2010.

19. Burkinshaw S, Son Y-A. The dyeing of supermicrofibre nylon with acid and vat dyes. Dyes and Pigments. 87(2), 132-8, 2010.

20. Hassan MM, Bhagvandas M. Sustainable low liquor ratio dyeing of wool with acid dyes: Effect of auxiliaries on agglomeration of dye molecules in a dyebath and dyeing uniformity. Journal of cleaner production. 152, 464-73, 2017.

21. Patel HM, Dixit BC. Synthesis, characterization and dyeing assessment of novel acid azo dyes and mordent acid azo dyes based on 2-hydroxy-4-methoxybenzophenone-5-sulfonic acid on wool and silk fabrics. Journal of Saudi Chemical Society. 18(5), 507-12, 2014;

22. Jocic D, Vílchez S, Topalovic T, Navarro A, Jovancic $\mathrm{P}$, Julia MR, et al. Chitosan/acid dye interactions in wool dyeing system. Carbohydrate Polymers. 60(1), 51-9, 2005.

23. Siddiqua UH, Ali S, Iqbal M, Hussain T. Relationship between structure and dyeing properties of reactive dyes for cotton dyeing. Journal of Molecular Liquids. 241, 839-44, 2017.

24. Mu B, Liu L, Li W, Yang Y. High sorption of reactive dyes onto cotton controlled by chemical potential gradient for reduction of dyeing effluents. Journal of environmental management.239, 271-8, 2019.

25. Hauser PJ, Tabba AH. Improving the environmental and economic aspects of cotton dyeing using a J. Text. Color. Polym. Sci. 16, No. 1 (2019) 
cationised cotton. Coloration Technology. 117(5), $282-8,2001$

26. Chung Y-S, Lee K-K, Kim J-W. Durable press and antimicrobial finishing of cotton fabrics with a citric acid and chitosan treatment. Textile Research Journal. 68(10), 772-5, 1998.

27. Kamel M, El Zawahry M, Ahmed N, Abdelghaffar F. Ultrasonic dyeing of cationized cotton fabric with natural dye. Part 1: Cationization of cotton using Solfix E. Ultrasonics Sonochemistry. 16(2), 243-9, 2009.

28. Nallathambi A, Venkateshwarapuram Rengaswami GD. Industrial scale salt-free reactive dyeing of cationized cotton fabric with different reactive dye chemistry. Carbohydrate Polymers. 174, 137-45, 2017.

29. Zhang F, Chen Y, Lin H, Lu Y. Synthesis of an amino-terminated hyperbranched polymer and its application in reactive dyeing on cotton as a salt-free dyeing auxiliary. Coloration Technology. 123(6), 351-7, 2007.

30. Rehan M, El-Naggar ME, Mashaly H, Wilken R. Nanocomposites based on chitosan/silver/clay for durable multi-functional properties of cotton fabrics. Carbohydrate polymers. 182, 29-41, 2018.

31. Karahan H, Özdoğan E, Demir A, Ayhan H, Seventekin N. Effects of atmospheric plasma treatment on the dyeability of cotton fabrics by acid dyes. Coloration technology. 124(2),106-10, 2008.

32. Elshaarawy RF, Seif GA, El-Naggar ME, Mostafa TB, El-Sawi EA. In-situ and ex-situ synthesis of poly-(imidazolium vanillyl)-grafted chitosan/silver nanobiocomposites for safe antibacterial finishing of cotton fabrics. European Polymer Journal. 116, 210-21, 2019.

33. Cheng X, Ma K, Li R, Ren X, Huang T. Antimicrobial coating of modified chitosan onto cotton fabrics. Applied Surface Science. 309, 138-43, 2014.

34. Scacchetti FA, Pinto E, Soares GM. Preparation and characterization of cotton fabrics with antimicrobial properties through the application of chitosan/silver-zeolite film. Procedia Engineering. 200, 276-82, 2017.

35. Xu Q, Ke X, Shen L, Ge N, Zhang Y, Fu F, et al. Surface modification by carboxymethy chitosan via pad-dry-cure method for binding Ag NPs onto cotton fabric. International Journal of biological macromolecules. 111, 796-803, 2018.

36. Gabriel JS, Gonzaga VA, Poli AL, Schmitt CC. Photochemical synthesis of silver nanoparticles on chitosans/montmorillonite nanocomposite films and antibacterial activity. Carbohydrate polymers. 171, 202-10, 2017.

(Received / / ; accepted / / )

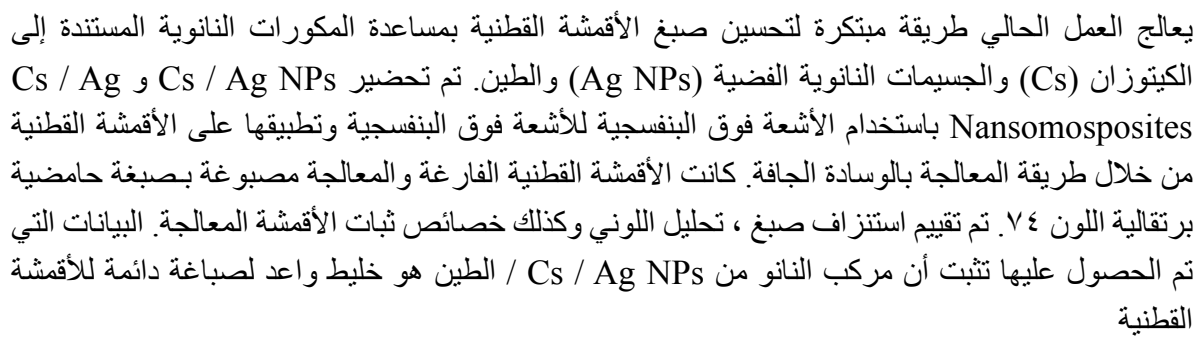

